\title{
Scientific Respiratory Symposium, Paris June 2010
}

\author{
This article was published in the following Dove Press journal: \\ Journal of Asthma and Allergy \\ 28 June 2011 \\ Number of times this article has been viewed
}

\author{
Gavin Dalglish \\ Graham Priestley \\ Horizon Medical Publishing, \\ Chichester, UK
}

Correspondence: Graham Priestley Golden Cross House, 3 Little London, Chichester, UK

Tel +44845 521 0268

Fax+447006023828

Email gp@horizonmedical.biz

\begin{abstract}
At a 2010 Respiratory Symposium in Paris, chaired by Professors Bousquet and Roche of the University of Paris, recent trends in research, therapy and treatment guidelines for asthma and chronic obstructive pulmonary disease (COPD) were reviewed and discussed by a faculty of expert European and US respiratory physicians. This article reviews five key clinical presentations with particular emphasis given to the importance of small airways in the pathology and treatment of asthma and COPD. Further analysis of the economics of treatment in Europe and the US shows a wide variance in direct and indirect costs.
\end{abstract}

Keywords: COPD, asthma, small airways, real-life clinical practice

\section{Introduction}

At the 2010 Teva Respiratory Symposium in Paris, chaired by Professors Bousquet and Roche of the University of Paris, recent trends in research, therapy and treatment guidelines for asthma and chronic obstructive pulmonary disease were reviewed and discussed by a faculty of expert European and US Respiratory physicians and an audience of general practice respiratory specialists. Professor Bousquet reminded the delegates that respiratory diseases, in global healthcare terms, are among the greatest challenges facing the medical world; the future potential economic cost of these diseases and their treatment is almost incalculable in scale, and the importance of correctly evaluating and selecting appropriate treatment strategies must not be underestimated.

Current guidelines may, as eminent expert commentators have recently said, be based on too narrow a view of evidence. Recognition of the greater importance of small airways in the mechanisms of respiratory diseases than previously understood, and the consequences for effective therapy, was a common topic in the presentations and workshops. True effectiveness of treatment outcomes delivered in clinical practice, rather than in the narrow focus of randomized, controlled clinical trials (RCTs), is a key issue impacting on choice of therapy, economic benefit and the development of improved inhaled therapy technologies. The scope and utility of different approaches to clinical assessment and reporting in published trials and investigations was a well-received topic, as the relevance of RCT evidence in isolation to outcomes in real-life clinical practice is increasingly under question. A summary of each presentation follows.

\section{Treating all the airways Professor R Dahl, Aarhus University Hospital, Denmark}

The importance of small airways in the pathology and treatment of asthma has been underestimated in the past. Historically, there are a number of practical reasons for 
this; health providers like to have a simple basis to measure the success of treatment strategies; measuring forced expiratory volume in 1 second $\left(\mathrm{FEV}_{1}\right)$, which is a simple procedure, has been the standard applied to judge the success of treatment in respiratory conditions such as asthma and chronic obstructive pulmonary disease (COPD). A critical examination of the validity of $\mathrm{FEV}_{1}$ reveals, however, that it has a poor correlation with health outcomes, though various statistical techniques have been used to manipulate the data to demonstrate otherwise.

Conventionally, the airways are divided into large (lumen diameter $>2 \mathrm{~mm}$ ) and small (lumen diameter $<2 \mathrm{~mm}$ ). This is an entirely arbitrary measurement, which was chosen simply because the original investigators had a minimum catheter size of $2 \mathrm{~mm}$, so could not go any further than the first 7 divisions - there are in fact 14 to 17 more branch generations after $2 \mathrm{~mm}$. Measurement of the small airways is difficult, since after each division the lumen decreases in diameter to 0.69 of the previous branch, $\mathrm{FEV}_{1}$ has been favored because it is relatively easy to measure; however, it primarily measures effects on the large central airways, those with a lumen diameter of $>2 \mathrm{~mm}$. Examination of the pathology in disease conditions such as bronchial asthma and COPD shows that the changes are much greater in the small airways ( $<2 \mathrm{~mm}$ diameter), with thickening of the lumen, much more mucus in the lumen, and more inflammatory changes. Whereas the inflammation in the large airways is inside the smooth muscle layer, close to the lumen, in the small airways it is much more in the outer circumference, which makes them more freely moveable, and so vulnerable to total collapse.

In COPD the same difference is found - thickening of the peripheral airways with smooth muscle hypertrophy and chronic airways inflammation. In COPD there are also emphysematous changes; the mucus increases resistance to airflow, there is goblet cell and gland hypertrophy, a remodeling of the airways with smooth muscle hypertrophy, whereas in asthma the alveoli themselves are not so involved, and in COPD they seem to gradually disappear without an obvious explanation. ${ }^{1,2}$

In a study of airway obstruction in pulmonary disease, in normal subjects, the ratio of peripheral resistance (Rp) to total lung resistance was 0.24 during inspiration. ${ }^{3}$ Patients with bronchial asthma without airflow obstruction showed values of central resistance (Rc) and Rp similar to those of normal subjects. Rp but not Rc significantly increased in patients with bronchial asthma with obstruction and in COPD. This implies that peripheral airways are the predominant site of airflow obstruction, irrespective of chronic airflow obstruction pathogenesis.

The question of effective treatment of asthma and COPD therefore needs to be examined with reference to the composition of the lungs as described, and to the distribution of the pathology. Considering inhalers, 3 groups of factors affect the deposition: device factors such as actuation method, resistance, and plume speed; patient factors such as inhalation technique, inspired volume and flow, breath hold pause, and airways disease type and severity; and formulation characteristics - particle size, density, charge, and hygroscopicity. If we want to treat the whole of the airways using inhalers, there are clearly issues with particle size, as larger particles may not penetrate the smallest airways easily, where most of the pathology is to be found.

Studies have shown that the peripheral distribution is affected by speed of inhalation; rapid inhalation tends to lead to early deposition of drug in the oropharynx or large airways, with correspondingly less available to penetrate the small airways. So not only does total lung deposition vary with the content of the inhaler ${ }^{4}$ - drug, propellant, and aerosol or powder - but also the distribution of the deposition within the lung in relationship to the areas most affected by disease. The particles in different inhalers vary from 1 to $5 \mu \mathrm{m}$, so called "respirable" particles are $<6 \mu \mathrm{m}$. There are specific areas where the different sizes will deposit; at $2 \mu \mathrm{m}$ they will be deposited in both the small and large airways, whereas larger particles will largely be deposited centrally and will not reach the peripheral airways. In asthmatics, there is increased smooth muscle volume and inflammation, which will be largely in the small airways, which is where we need to get to the receptors, either the $\mathrm{B}_{2}$ receptors for bronchodilator treatment or the steroid receptors for anti-inflammatory activity, and these can be reached only by small particles or via the bloodstream. ${ }^{5}$ The difference between beclomethasone diproprionate (BDP) in a chlorofluorocarbon (CFC) or hydrofluoroalkane (HFA) inhaler demonstrates the difference in deposition, ${ }^{6,7}$ as do the Gamma recordings of aerosols of different diameter salbutamol particles. ${ }^{8}$ In another study, patients inhaled fluticasone before lung resection surgery. The fluticasone concentrations were high in the central airway tissue, while concentrations in the peripheral lung tissue were low. ${ }^{8}$ The particle size affects not only the distribution, but also the total dose deposited in the lungs rather than in the oropharynx; measurements taken with different inhalers demonstrate these significant differences, ${ }^{9}$ as does a comparison of BDP-CFC-free (Qvar ${ }^{\circledR}$, Teva Pharmaceutical Industries Limited, Petach Tikva, Israel), an HFA formulation of BDP, and a CFC-BDP inhaler. ${ }^{10-12}$ 
A further factor that can affect the dose and distribution of drug deposition is speed of inhalation; fast inhalation results in greater impaction of particles in the oropharynx, but this is also particle-size dependent, as smaller particles can follow the airflow more easily. Formulations with a greater number of smaller particles are therefore less affected by the variation in patient inhalation speed on the total lung deposition, having negligible oropharyngeal deposition. ${ }^{13}$

To determine whether small airway inflammation should be specifically targeted for treatment in asthma therapy, two groups of patients were compared; one group with severe asthma but who did not suffer frequent exacerbations, and a group with difficult-to-control asthma who had frequent exacerbations. ${ }^{14}$ The differences detected were primarily in small airways inflammation, with significantly higher levels of inflammation in distal areas of the lung in patients who had frequent exacerbations, which was confirmed in another study showing significantly more evidence of distal inflammation in patients with refractory asthma. ${ }^{15}$

In conclusion, it is important to consider the involvement and importance of small airways in asthma and COPD, selecting inhaled treatments that have the ability to reach all the airways, including the distal airways.

\section{Small patients - small airways? Monitoring asthma in children Professor Wim Van Aalderen, Vice Chairman, Emma Childrens' Hospital AMC Amsterdam, The Netherlands}

The objectives of this presentation were to outline the history and guidelines of treatment of asthma in children, to review the treatments available, and to highlight some factors that should be considered in making treatment effective and appropriate in young patients.

In the 1950s it was shown that corticosteroids were effective in the treatment of asthma; in the 1970s the first inhaled corticosteroids (ICS) - betamethasone and budesonide came to the market. Formulations were improved over the next 20 years, with the small-particle ICS introduced in the 1990s. The earliest study of budesonide vs salbutamol was made with the aim of discovering whether interfering with the autonomic nervous system was better than treating the inflammation, which was known by this time to affect the airway wall. ${ }^{16}$ The ICS proved far better than treatment with a short-acting $\beta$-agonist, demonstrating that bronchial hyperresponsiveness decreased over the months of treatment in moderate to severely asthmatic children. Symptoms were reduced within 2 weeks, $\mathrm{FEV}_{1}$ improved within 2 to 4 weeks and then reached a plateau, and hyper-responsiveness continued to improve. Perhaps most importantly, exacerbations were reduced. This was confirmed in many studies, and is why these treatments are now cornerstones of asthma therapy. The studies continued with a comparison of children who continued to take the treatment and children from whom the treatment was withdrawn, and a return to baseline values in the untreated children demonstrated that control of asthma with ICS treatment should continue for a long time.

GINA (the Global Initiative for Asthma Management and Prevention in Children $)^{17}$ defines the goal of asthma care as "to achieve and maintain control of the clinical manifestations of the disease for prolonged periods. When asthma is controlled, patients can prevent most attacks, avoid troublesome symptoms day and night, and keep physically active." The latest management guidelines in GINA incorporate inhaled corticosteroids as a core component in steps 2 to 4 of the 5-step recommendations for achieving asthma control in children and adolescents $>5$ years of age, and recommend that treatment should be stepped up until control is achieved and then maintained at that level.

Diagnosis and treatment of children under 5 years of age is a more difficult question; studies have shown that the younger the child, the greater the likelihood that an alternative diagnosis may explain recurrent wheeze, and that most children who wheeze will not continue to do so later in life. The management guidelines in GINA for this age-group have 3 steps, beginning with a $\beta$-agonist, adding in low-dose ICS or a leukotriene modifier as the second step, and in the third step both double-low-dose ICS and the leukotriene modifier. However, 2 years ago, studies by the European Respiratory Society Task Force added another dimension to the issue. ${ }^{18}$ These studies showed the existence of 2 asthma phenotypes in young children. One is episodic (viral) wheeze - wheezing during discrete time periods, often in association with clinical evidence of a viral cold, with absence of wheeze between episodes. The other, much more resembling classical asthma in older children and adults, is multiple-trigger wheeze - wheezing that shows discrete exacerbations, but also symptoms between episodes. From the literature, it is known that the effectiveness of treatment with ICS is inconclusive in the episodic wheeze group, but in the second group treatment appears to be more effective, especially in the more allergic phenotype, though less effective than in older children with allergic asthma.

Are small particles better for small children? First there is the scientific evidence. A modeling study from Rotterdam 
simulating a child's in vitro inhalation through a metered dose inhaler (pMDI) and spacer which measured the lung dose during tidal breathing of a large-particle formulation of BDP and of a small-particle HFA-BDP. Lung deposition was significantly higher with the small-particle HFA-BDP and rose with increases in tidal volume, in contrast to the CFC-BDP, which fell. ${ }^{19}$ Further in vivo studies in young children have demonstrated greater deposition with small particles than large, independently of tidal volume, and that deposition with large particles resulted in higher deposition with increasing age. ${ }^{20-26}$ The studies used a number of methods, including radiolabeling and urinary excretion measurements.

Secondly there is the clinical evidence. Characteristically, children with severe or difficult-to-control asthma and frequent exacerbations will have "normal" lung function, ie, as measured with $\mathrm{FEV}_{1}$, which is largely an indicator of large airway involvement. Hyperinflation is common, and it appears that distal airway impairment is more pronounced than proximal airway impairment. A US study in 50 centers of children 5 to 12 years of age with stable, moderate, symptomatic asthma control receiving short-acting $\beta_{2}$-agonists on an as-needed basis were treated with HFA-BDP $\left(\right.$ Qvar $\left.^{\circledR}\right)$ at lower doses $(80 \mu \mathrm{g})$ than normally used with CFC-BDP $(160 \mu \mathrm{g})$ were entered into a randomized, double-blind, placebo-controlled 12 -week study. ${ }^{27}$ The children had FEV between $50 \%$ and $80 \%$ of predicted and bronchodilator reversibility of $>12 \%$. The primary outcome was the mean change in $\mathrm{FEV}_{1}$ (\% predicted) from baseline at 12 weeks compared with placebo, and the result was that low-dose HFA-BDP achieved significantly greater increase in $\mathrm{FEV}_{1}$ $(9.2 \%)$ than placebo $(3.9 \%)(P \leq 0.01)$. Plasma cortisol levels at 12 weeks were increased for all groups (HFA-BDP $80 \mu \mathrm{g}$, HFA-BDP $160 \mu \mathrm{g}$, and placebo) but that the two HFA-BDP groups had levels below the reference range after 12 weeks compared with placebo, indicating the high safety level of the therapy. In a comparison of HFA-BDP with fluticasone, a 3-stage trial of control with 50\% dose reductions at each stage for good control, continued dosage for intermediate control, and discontinuation for poor control demonstrated equivalent or better results for HFA-BDP compared with fluticasone. ${ }^{28} \mathrm{~A}$ trial comparing HFA-BDP with CFC-BDP and budesonide in a 1:2 dose ratio in school children demonstrated equivalent efficacy for HFA-BDP at half dosage of the conventional inhaled steroid therapy. ${ }^{29}$ There are no clinical studies in pre-school age children.

The anatomical and physiological differences between children and adults are important; the pharynx and supraglottic area are less rigid in children, the epiglottis narrower, floppier, and closer to the palate and the larynx higher and closer to the base of the tongue. Absolute airway diameter is smaller in young children, with the result that airway resistance increases (Hagen-Poiseuille's law states $\times 16$ for a $50 \%$ reduction in radius), and the airways are more prone to obstruction and harder to reach. In addition, infants breathe through the nose, making delivery of inhaled drugs difficult, and young children have a higher respiratory rate, reducing the residence time of inhaled particles in the airways. When the particle size for inhaled drugs was chosen, it was based on a size for adults of 2 to $5 \mu \mathrm{m}$; in children, with smaller airways, this should be 0.75 to $1.2 \mu \mathrm{m} .^{30}$

\section{Are small particles better for children?}

Small particles are less likely to impact in the upper respiratory tract, they have a longer residence time in the airways, with deposition through sedimentation, they are deposited more uniformly, and, quantitatively, produce better deposition as demonstrated both in vitro and in vivo. A commonly held view of pediatricians was that if a child starts crying the deposition will be better; 5 studies have demonstrated that the opposite is, in fact, true; crying deposition is low or negligible. If a face mask is being used and the child is turning their head, there is no deposition at all.

\section{Side effects}

A number of studies have compared HFA-BDP ultrafine particle therapy $\left(\mathrm{Qvar}^{\circledR}\right)$ with fluticasone, CFC-BDP, and budesonide in children to establish the potential for sideeffects such as growth retardation and HPA-axis effects; in all cases no significantly greater potential risks were found at normal therapeutic doses. . $^{28,31,32}$

\section{Summary}

Summarizing the critical requirements for inhaled asthma treatment:

- predictable and reproducible dose delivery,

- effective lung deposition,

- maximal clinical effect, minimal side effects,

- simple devices with minimal demands (co-ordination and co-operation).

The three questions that need to be answered are: is active inhalation possible, is there sufficient inspiratory flow, and is there good hand/lung co-ordination? If there is no active flow, as in very young children, we can give a pMDI plus a spacer or a nebulizer; if there is active inhalation but insufficient inspiratory flow we can give the same or a breath-actuated aerosol; if there is sufficient inspiratory flow we can also give a dry-powder 
inhaler (DPI); in pediatrics, hand-lung co-ordination is rarely good enough to give a pMDI without a spacer.

\section{Conclusion}

In conclusion, ICS treatment is effective with school children in asthma. It is effective in children with multiple-trigger wheeze. BDP CFC-free $\left(\right.$ Qvar $\left.^{\circledR}\right)$ in children $\left(\right.$ Qvar $^{\circledR}$ is licensed for use in many European countries for adults and children aged 5 to 12 years of age but in other countries such as the UK, it is licensed only for use in adults including the elderly). is as effective as fluticasone in a one-to-one ratio, and as effective as budesonide in a one-to-two ratio. Most studies indicate that BDP CFC-free deposition is better in pre-school children, although unfortunately there are no studies of clinical effectiveness in preschool children.

\section{Inhaled corticosteroid effect on severe asthma and COPD Professor Richard J Martin, MD, Chairman, Department of Medicine, Edelstein Chair in Pulmonary Medicine, National Jewish Health}

In asthma, refractory asthma patients are the most challenging regarding response to ICS. There are many reasons why patients do not respond well to ICS; in this symposium we are focusing on the issue of the small or distal airways.

The first question to ask is whether there is supporting anatomic evidence that the distal airways are involved in asthma and to a different extent than the central airways?

The question of "remodeling" of the airways is an important issue as the resulting airway changes can cause an inability to achieve normal lung function. A post-mortem study compared the outer wall area of a control population, of asthmatics who died from causes other than their asthma, and of patients who died from asthma. ${ }^{33}$ In the medium-size airways, 2 to $4 \mathrm{~mm}$, there was no statistically significant difference between groups. In the more peripheral lung, $<2 \mathrm{~mm}$, both asthma groups had significantly increased outer wall area compared with the control population, but there was no difference between the two asthma groups. This suggests that, regardless of the severity of asthma, remodeling changes occur in the distal lung.

Another post-mortem evaluation used a bronchogram technique to visualize the airways of 3 subjects, 1 who suffered fatal asthma, 1 whose asthma had been "well controlled," and 1 normal, nonasthmatic control. The fatal asthma case clearly had blockages of the major airways that would have prevented gas exchange. The "well-controlled" asthma patient, who died from other causes than asthma, had fine branching of the airways but little evidence of penetration in the alveoli by the marker dye used. The normal individual had fine branching of the airways with clearly visible dye reaching the alveolar space. This demonstrated that even in "well-controlled" asthma, anatomic abnormalities occur in the distal airways.

Is there supporting physiological and clinical evidence that the central and distal airways differ in asthma?

A physiological evaluation of peripheral airway resistance showed that even in mild asthmatics this was markedly elevated compared with normal controls. ${ }^{34}$ After bronchodilator therapy, this was still significantly elevated. Thus, physiological differences of distal lung dysfunction are apparent even in mild asthma.

A physiological study of asthmatic children demonstrated differences in the distal airways between children with stable asthma and children who had exacerbations. ${ }^{34}$ No significant differences in $\mathrm{FEV}_{1}$, total lung capacity, functional residual capacity, or residual volume were found, but there was significantly elevated closing volume in the unstable asthma group. If a child with an elevated closing volume is to encounter an asthmatic trigger such as an upper respiratory infection or allergen, this could result in closure of the distal airways due to this instability, and consequently an exacerbation.

Since a major characteristic of asthma is airway inflammation, is there physiological evidence to support a differentiation between central and distal inflammation?

Tests during the early morning hours have been carried out to detect differences in the circadian rhythm airway reactivity. Even asthma patients who do not have excessive overnight falls in lung function still have approximately twofold increases in bronchial hyper-responsiveness. In asthma patients who have large night-time falls in lung function, bronchial hyper-responsiveness can increase by 8 times.

By measuring the relationship between lung volume and airways resistance asleep and awake, changes in the distal lung function of asthma patients can be detected. ${ }^{35}$ Increasing lung volume will normally result in decreasing resistance, a relationship that continues to hold in waking asthma patients whether upright or reclined. During sleep, however, the relationship starts to break down, with resistance maintained despite increase in lung volume. This suggests that distal inflammation and edema are responsible for this physiological uncoupling of the lung parenchyma and airways in asthma. This "nocturnal uncoupling?" of volume and resistance was supported by a difference in proximal and distal inflammation in a bronchoscopy study carried out in an asthma control population who did 
not have worsening asthma at night and another that did. Biopsies were performed at 16:00 and 04:00 hours in the fifth generation airway and the alveolar tissue area. ${ }^{36}$ During the afternoon study, there were no statistically significant differences between groups or locations in the inflammatory response. At 04:00 hours the volume of eosinophils in the alveolar tissue area was tremendously increased in the nocturnal asthma group. These studies demonstrated that uncoupling of the airways and lung parenchyma occurs at night, resulting from the inflammatory response being the greatest in the distal airways.

Does particle size of inhaled medication alter lung physiology and inflammation? There is a wide variation in particle size between the available ICS medications, ranging from $1 \mu \mathrm{m}$ to $>4 \mu \mathrm{m}$, and between aerosols in solution and in suspension. Lung deposition studies demonstrate a clear trend for greater deposition with smaller particle size, with the ultra-fine particle in HFA-BDP (Qvar ${ }^{\circledR}$ ) resulting in deposition rates in excess of $50 \%$ of the dose, while the $3.5 \mu \mathrm{m}$ particles of BDP-CFC can result in deposition rate as low as 4\%. ${ }^{6,7}$ Air-trapping, measured as lung attenuation, has been clearly demonstrated to be significantly less changed after treatment with CFC-BDP than with HFA-BDP treatment. $^{37}$

In conclusion, there is supporting physiologic and clinical evidence that the central and distal airways are different in asthma, that there is a differentiation between central and distal inflammation, that the particle size of inhaled medication alters deposition, and that particle size of inhaled medication alter lung physiology and inflammation.

Does particle size of inhaled medication alter asthma outcome? The short-term studies of 4 to 12 weeks suggest that the answer is yes, but longer-term studies are needed to confirm these observations.

The question of the use of ICS in COPD is more difficult than for asthma; there are arguments both for and against. ${ }^{38}$ They are licensed for use in COPD in Germany, Austria, Switzerland, and the US. It should be noted that ICS are not licensed for COPD in France, and the UK only in combination with a long-acting beta agonist.

The first part of the problem is that the COPD phenotypes are not well understood, and that the disease has a complex pattern of airway vs parenchymal vs mixed vs inflammation dimensions. There is emphysema-predominant COPD, with centrilobular emphysema, panlobular emphysema, paraseptal emphysema, and bulla. There is also airway-predominant COPD, with large and small airway disease, air trapping bronchial wall thickening, bronchial dilatation, mucus, and airway collapse. ${ }^{39}$ In some of these pathologies steroid treatment does not have a logical therapeutic role and may indeed be potentially harmful.

As studies of ICS therapy for managing COPD have yielded conflicting results for survival and risk of adverse events, a systematic review and meta-analysis of the available randomized, controlled trials was published in $2008 .{ }^{40}$ Eleven studies, including 14,426 subjects, were selected, all of more than six months duration, to form a comparison of ICS with nonsteroid inhaled medication for COPD. One-year all-cause mortality was not found to be significantly different between the two treatment groups, but the risk of pneumonia was significantly higher in the ICS group. Subsets of patients for whom the pneumonia risk was found to be greater were:

- $\quad$ ICS dose $>100 \mu \mathrm{g}$ (BDP equivalents),

- Shorter duration of ICS use $<2$ years,

- $\mathrm{FEV}_{1}<40 \%$ predicted,

- Combined ICS and bronchodilator therapy.

Further investigation is needed to determine which COPD patents would benefit from the use of chronic ICS.

\section{Economic issues in asthma and COPD: disease burden, treatment and management \\ Andrew Briggs, Public Health and Health Policy, University of Glasgow}

Health economics is concerned with broad issues of the relationship between cost and benefit over the whole spectrum of illness and healthcare, both direct and indirect. Examining such issues in a wider sense than purely medical extends to all aspects of the impact of illness and treatment in general economic terms.

In this way it is possible to compare respiratory disease treatment, for example, with treatment of cardiac conditions. As health economists we are concerned also with the benefits of treatment not only in terms of survival but in more subjective and difficult to measure areas such as quality of life.

Three topics were discussed in this presentation: the burden of disease in COPD, which was the subject of a recently conducted analysis; two specific Health Economic evaluations, TORCH in COPD and GOAL in asthma (see below); and a particular example of economic analysis of the impact of inhaler devices and technique in asthma management.

\section{COPD: the economic burden of the disease}

The direct financial cost to the health service of COPD in the UK is estimated at $£ 486$ to $£ 850$ million, alternatively 
viewed as $£ 780$ to $£ 1,150$ per patient per year. ${ }^{41}$ The indirect costs, ie, of lost productivity within the labor market, could double this, since $44 \%$ of COPD patients are below retirement age and $24 \%$ of these are prevented from working through COPD. For patients not of working age, $5 \%$ of the patients' carers missed work to provide care. ${ }^{42}$

In Scotland, unusually detailed information is available for a prospective cohort of 15,402 men and women recruited over the 4 years from 1972 to 1976 , giving baseline data including spirometry for each participant and more than 30 years follow-up on mortality and. $\mathrm{FEV}_{1}$, while having limits in its value in clinical medicine, is linked to survival, and this was seen in the correlation of $\mathrm{FEV}_{1}$ with survival in the midspan. There was clear separation between the groups in this cohort, even after correction for age and other factors. ${ }^{43}$

There have been changes in the mix of treatments in COPD over time, with significant increase in awareness of COPD over last 10 years. Changes to both the management and treatment of COPD have occurred, with the issue of guidelines: British Thoracic Society (BTS)/Scottish Intercollegiate Guidelines Network (SIGN) first in 1997, followed by GOLD (2001, updated 2006) and NICE (2004). New drug treatments, both through licensing of new products and particularly combination products, are probably responsible for the most important changes in treatment patterns. Changes in management have included the General Medical Services Contract, with rewards to clinical practices for diagnosis of COPD, diagnosis confirmed by spirometry and ongoing management. These changes in therapy and management have had a large impact on the cost; a discussion with respiratory physicians has revealed that the "basket of products" used routinely in the management of COPD today is approximately 7 times the cost of the products used 5 years ago.

So much for the disease burden; as health economists we are not concerned quite as much with the burden itself as on what effect management of the disease has in changing that burden. Two examples of this economic evaluation of management follow:

\section{Example I: GOAL (the Gaining Optimal Asthma control) 44,45 study (asthma)}

This study was set up to test prospectively whether sustained asthma control assessed using a composite measure derived from GINA/NIH (National Institutes for Health) guidelines is achievable. The idea was to aim for total control of asthma and to study how far particular pharmaceutical products advanced outcomes towards that target. The main comparison was between fluticasone propionate alone versus fluticasone propionate in combination with salmeterol. The original clinical trial results were published in 2004 and the economic analysis 2 years later.

The results show that the combination therapy produced a higher proportion of patients spending time in the higher control states, but that treatment costs were higher, with only a very small benefit from lower health care costs, but that there was a significant gain in quality of life.

The value message that comes out is very positive, considered in the light of NICE evaluations looking for $£ 20,000$ to $£ 30,000$ per quality-adjusted life year (QUALY) - the combination treatment achieving $£ 5,000$ to $£ 8,000$ per QUALY benefit over the fluticasone propionate treatment alone. The study demonstrated the value of the combination product through the benefit obtained, not through cost offsets achieved.

\section{Example 2: The TORCH ${ }^{46,47}$ study (COPD)}

TORCH (TOward a Revolution in COPD Health) was a 3-year, international, multicenter, placebo-controlled, doubleblind, randomized, parallel group trial. The first patient was recruited in 2000, with results becoming available in 2006 . The TORCH study recruited patients from 444 centers in a total of 42 countries worldwide, including the Americas, Europe, Australasia, Asia, and Africa.

Patients with moderate-to-severe COPD were recruited. The inclusion criteria for patients in $\mathrm{TORCH}$ were: age 40 to 80 years, an established clinical history of COPD, a smoking history of $\leq 10$ pack-years, baseline $\mathrm{FEV}_{1}<60 \%$ predicted (prebronchodilator), $<10 \%$ reversibility in predicted $\mathrm{FEV}_{1}$ and $\mathrm{FEV}_{1}$ /forced vital capacity (FVC) ratio $\leq 70 \%$.

The study design included a 2-week run-in period, a 3-year treatment phase, and a 2-week follow-up phase. Patients were randomized to 1 of the following 4 treatment groups, all administered twice daily via the Diskus ${ }^{\circledR}$ DPI device (GlaxoSmithKline, UK): placebo, salmeterol $50 \mu \mathrm{g}$, a long-acting beta- 2 agonist, fluticasone propionate $500 \mu \mathrm{g}$, an ICS, and salmeterol/fluticasone propionate 50/500 $\mu \mathrm{g}$.

The pooled results, cost by region, and QUALYs by region are shown in Table 1. Notably, all costs are very much greater in the US than in all other regions, but this must be balanced by awareness of willingness to pay much higher health costs; in the graphical view of the final results (Figure 1), the very much higher figures for the US need to be related to a usual acceptable figure of $\$ 100,000$ per QUALY in that region. This absolute cost difference discounted, the ratio of comparative cost per QUALY, represented by the steepness of the line is 
Table I TORCH:47 pooled costs per region and QUALYs per region

\begin{tabular}{|c|c|c|c|c|c|c|c|c|c|}
\hline & \multicolumn{4}{|c|}{ Pooled results, EQ-5D countries } & & \multicolumn{4}{|c|}{ Cost by region, EQ-5D countries* } \\
\hline & \multicolumn{2}{|c|}{ Cost (\$US)* } & \multicolumn{2}{|c|}{ QALYs } & & \multirow[b]{2}{*}{ PL } & \multirow[b]{2}{*}{ SAL } & \multirow[b]{2}{*}{$\mathbf{F P}$} & \multirow[b]{2}{*}{ SFC } \\
\hline & Mean & SE & Mean & SE & & & & & \\
\hline PL & 9,467 & 584 & 1.941 & 0.020 & US & $|8,24|$ & 21,787 & 21,188 & 25,196 \\
\hline SAL & 10,995 & 552 & 1.949 & 0.019 & E Eur & 4,403 & $6,|4|$ & 6,883 & 7,196 \\
\hline FP & 11,520 & 619 & 1.965 & 0.019 & W Eur & 5,856 & 6,209 & 6,886 & 7,290 \\
\hline SFC & 12,950 & 586 & 2.022 & 0.018 & Other & 3,993 & 5,423 & 5,423 & 7,006 \\
\hline
\end{tabular}

Notes: *Local Currencies translated into $\$$ US by use of purchasing power parity statistics; adapted from Briggs et al. ${ }^{47}$

Abbreviations: PL, placebo; SAL, salmeterol; FP, fluticasone proprionate; SFC, salmeterol plus fluticasone proprionate.

similar across the regions and demonstrated the superiority of the combination product over the components.

\section{Management and delivery}

Health economic evaluations in these and other studies of managing delivery of respiratory treatment are providing emerging evidence that devices are important, largely observational at present, but important for hypothesis generation, which perhaps should lead to this topic making a step up the evidence hierarchy, as other commentators at this meeting have also suggested. Inhaler technique is similarly important, often being confounded with the effects of the medication being delivered, which is a challenging area for analysis; as in a similar way there is a relationship with getting the drugs into the right place in the lungs, the importance of which is evident from earlier presentations at this meeting.

There is a clear potential for devices and delivery techniques to be demonstrably cost-effective, allowing better use of existing therapies, particularly in the light of the ever-increasing cost of combination therapies. Evidence is required that would then justify investment in improvements of technique and delivery vehicle. Analyses such as GOAL illustrate the potential framework for providing evidence of their value by evaluating the way that treatment acts on control, as improved control improves health-related quality of life and reduces costs, creating a real value message.

\section{Summary}

Respiratory disease creates a clear burden to society in health care costs, days off work, morbidity, and mortality. Cost effectiveness analysis is required to show value of new treatment interventions; public health services cannot afford to provide all new treatments that are presented to them, particularly in this time of fiscal restraint and national debt issues. Devices and improved inhaler technique offer the potential for better use of existing effective therapies, and should be evaluated head-to-head in randomized clinical trials with new drug therapies.

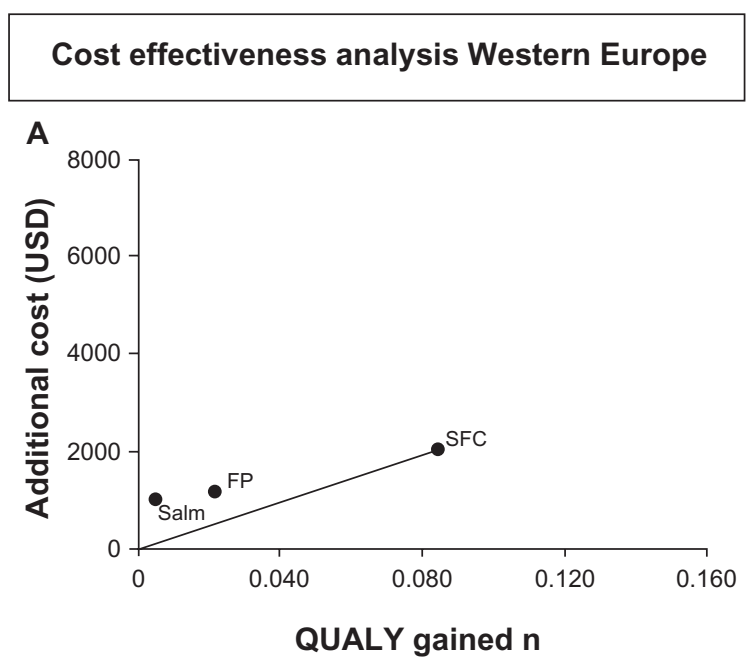

\section{Cost effectiveness analysis United States}

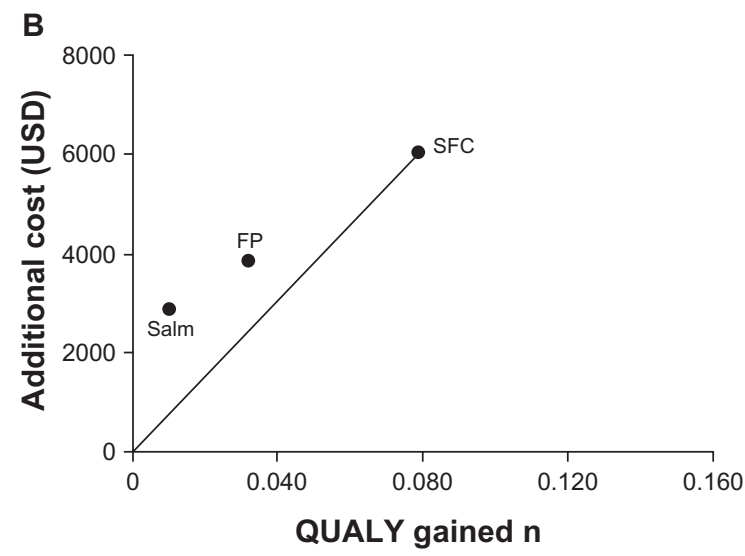

Figure I TORCH: ${ }^{47}$ cost effectiveness per QUALY gained.

Note: Reproduced with permission from the European Respiratory Society (C).

Abbreviations: PL, placebo; SAL, salmeterol; FP, fluticasone proprionate; SFC, salmeterol plus fluticasone proprionate. 


\section{Challenges in clinical practice}

Professor David Price, Professor of Primary Care

Respiratory Medicine, University of Aberdeen; Honorary

Professor University of Adelaide, International Primary

Care Research Group (IPCRG) research sub-committee

chair; Member of Allergic Rhinitis and its Impact

on Asthma (ARIA) executive, sessional respiratory

physician for children and adults, Norfolk, UK

This presentation sets out to challenge views about evidencebased medicine.

A typical grading of clinical evidence is shown in Table 2. The highest grading is therefore the RCT. Are such trials measuring effectiveness ... or efficacy? To define these terms, effectiveness would be the outcome for a real-world asthma patient - it would be what you would aim to achieve in day-to-day clinical practice. Efficacy would be the effect of a particular treatment on a patient in a clinical trial. The question is whether the efficacy achieved in that trial would be reflected in the effectiveness of treatment in everyday clinical practice.

To examine this question, in an asthma trial what patients can be selected for such a trial? As we know, a patient must have a clinical diagnosis of asthma, $15 \%$ reversibility, have adequate inhaler skills, have symptoms, have lung function between $50 \%$ and $80 \%$ of predicted, not smoke, not have significant rhinitis, not have reflux, not have heart disease, not have co-existing COPD, must be willing to take treatment

Table 2 Typical grading of clinical evidence

\begin{tabular}{|c|c|c|}
\hline $\begin{array}{l}\text { Grade of } \\
\text { recommendation }\end{array}$ & $\begin{array}{l}\text { Level of } \\
\text { evidence }\end{array}$ & \\
\hline \multirow[t]{6}{*}{ A } & la & Systematic review of RCTs \\
\hline & $\mathrm{Ib}$ & $\begin{array}{l}\text { Individual RCT (with narrow } \\
\text { confidence interval) }\end{array}$ \\
\hline & Ic & $\begin{array}{l}\text { All or none - patients die } \\
\text { without or live with }\end{array}$ \\
\hline & $2 a$ & $\begin{array}{l}\text { Systematic review of } \\
\text { cohort studies }\end{array}$ \\
\hline & $2 b$ & $\begin{array}{l}\text { Individual cohort study } \\
\text { (including low-quality RCT; } \\
\text { eg, <80\% follow-up) }\end{array}$ \\
\hline & $2 c$ & Outcomes research \\
\hline \multirow[t]{3}{*}{ C } & 3a & $\begin{array}{l}\text { Systematic review of } \\
\text { case-control studies }\end{array}$ \\
\hline & $3 b$ & Individual case-control study \\
\hline & 4 & $\begin{array}{l}\text { Case-series (and poor quality } \\
\text { cohort and case-control studies) }\end{array}$ \\
\hline D & 5 & $\begin{array}{l}\text { Expert opinion without explicit } \\
\text { critical appraisal, or based on } \\
\text { physiology, bench research or } \\
\text { first principles }\end{array}$ \\
\hline
\end{tabular}

regularly, to write a diary twice a day, and to come to the doctor once a month. The result of that trial will be a measure of efficacy. However, such a patient population is not reflective of real life - even the willingness to take part in a clinical trial would rule out many people. So this measure of efficacy needs to be tempered by results from a real-life population to understand effectiveness.

A real-life population would introduce the effect of compliance and adherence, which can be deliberate or nondeliberate, and be influenced by length of the treatment period, by inhaler technique, attitude to treatment, patient education and motivation, cost of treatment and many other factors. For example, in a double-blind trial in Sweden of inhaled steroids in children, though compliance normally decreases with time, $50 \%$ of the patients in the active arm were compliant at the end of the trial, after 2 years, a remarkable figure. ${ }^{48}$ Patients are smart enough to recognize when they are on the active treatment, and will keep on taking it. To get a real picture of effectiveness, we need to study for long enough to allow factors such as real-life compliance to become clear. So when we consider clinical trials, we should consider:

- The design of the study,

- The types of patients involved,

- The types of outcomes,

- How we should describe the data seen.

Professor Sir Michael Rawlins, the Chairman of the UK National Institute for Health and Clinical Excellence since 1999 (ex-Chairman of the Committee on Safety of Drugs), an eminent physician, recently said this to the UK Royal College of Physicians:

"Randomized controlled trials (RCTs), long regarded at the 'gold standard' of evidence, have been put on an undeserved pedestal. They should be replaced by a diversity of approaches that involve analyzing the totality of the evidence-base."

This statement challenges many people's thinking, which is something we need to do. To take an example, the authors of a trial published in the British Medical Journal ${ }^{49}$ made this statement:

"Parachutes reduce the risk of injury after gravitational challenge, but their effectiveness has not been proved with randomized controlled trials."

Which is a statement about a situation where a randomized clinical trial is clearly not possible. Clinical trials should not be a hierarchy, they should be regarded as complementary forms of evidence, be compared with each other, the evidence considered as a whole to consider what it means. 
To understand effectiveness we need 4 strands of evidence:

\section{Theoretical evidence}

This gives us give us a good model of why something might work; for example, knowing that inhaled steroids reduce inflammation in asthma.

\section{Classical double-blind, double-dummy RCTs}

These are the gold standard to prove efficacy; but we need to recognize that they do not represent real life, and tell us very little about effectiveness.

\section{Pragmatic trials}

Still randomized, but more like real life, with few patient exclusions (such as smokers, concomitant rhinitis, poor compliance), less frequent attendance, long study times. Still requiring consent and still rigorous, they still do not represent real life, but they help us to understand more, and are very useful for health economic analysis.

\section{Observational data}

These are gained from large databases such as the UK General Practice database (GPRD), which contains 3.5 million patients, with all their prescribing data, consultations, and hospitalizations. These are real-life patients; the weakness is that they are not randomized, although there are ways of handling this, such as matching patients.

These 4 different strands can each give different information.

\section{Other important design issues}

One of the weaknesses in many of our asthma and COPD trials is that they are not true "intention-to-treat analysis," because usually patients who stop treatment also drop out of the study - although the way people drop out of treatment is not random. True intention to treat keeps patients enrolled who are willing to continue supplying study data, thus giving opportunity to investigate reasons for dropping out or changing treatment, and to track eventual outcomes. Long duration of at least a year, real-life patients, and studies that mimic "real-life" clinical practice would also help in increasing the usefulness of trials. Only 2 examples of intention-to-treat clinical data from clinical studies in respiratory medicine were found: the $\mathrm{TORCH}^{50}$ and UPLIFT (Understanding Potential Long-term Impacts on Function with Tiotropium $)^{51}$ trials had an approach to mortality data different from other outcomes in these trials and in most other respiratory studies, giving long-term total mortality of all patients entering the trial rather than the standard approach where patients who stopped treatment would have been taken out of the studies. The results from TORCH show a "true" risk reduction of $17.5 \%$ rather than the $24 \%$ that would have been obtained from the standard approach, in UPLIFT $13 \%$ vs the $16 \%$ of the on-treatment approach. One could argue these are more realistic results.

\section{What types of patients?}

To quote Sir Michael Rawlins again:

"RCTs are often carried out on specific types of patients for a relatively short period of time, whereas in clinical practice the treatment will be used on a much greater variety of patients - often suffering from other medical conditions - and for much longer. There is a presumption that ... the benefits shown in an RCT can be extrapolated to a wide population; but there is abundant evidence to show that the ... value of an intervention is often missed in RCTs."

To take an example, if the first studies of ICS had been carried out in children with viral wheezing, or in smokers, we might have concluded that ICS do not work. Classical asthma RCTs have exclusions that reduce the eligibility of a normal, representative patient population by over $90 \%$; an example is a Norwegian asthma trial in which the exclusions resulted in only $1.2 \%$ of the patient population being eligible..$^{52}$

\section{Does it matter?}

Would using a wider range of patients make the results different? Surely, to categorize results from $1.2 \%$ of the patient population as "grade A" evidence is not sensible? We know that many things have a direct impact on asthma control, but are often excluded. We also know that inhaler technique has an impact on asthma control from a study that showed that poor ability to use inhalers was related directly to asthma control..$^{53}$ Other exclusions, such as rhinitis, smoking, and adherence, all affect asthma control. A cross-sectional study ${ }^{54}$ showed this, rhinitis patients being 4 times more likely to have poor asthma control.

We know that smoking reduces the effect of ICS for 3 reasons: smoking changes inflammation to a more neutrophilic pattern, ${ }^{55}$ it interferes with the mechanism of ICS through oxidative stress,${ }^{56}$ and it leads to the excess production of leukotrienes,${ }^{57}$ which we know are steroid-resistant. A GPRD database study of our own of the effect on smoking on asthma control showed that the chance of gaining control was $50 \%$ less for smokers with the use of increased ICS, 30\% less likely using long-acting beta- 2 agonists, and maintained benefit using leukotriene antagonists. Clearly, we 
need to include smokers in clinical trials so that we know how drugs work with them. So, I agree strongly with Sir Michael Rawlins - we need a breadth of asthma evidence, which would include a whole range of patients with a range of co-morbidities and severities, not just those with $15 \%$ reversibility, $\mathrm{FEV}_{1}$ between $50 \%$ and $80 \%$, and so on.

\section{What types of outcome?}

Does it matter? Is $\mathrm{FEV}_{1}$ a perfect measure? We heard in this meeting how poorly it correlates with symptoms. Is control enough? In a randomized, controlled trial comparing BTS/ SIGN-guideline-based treatment with sputum-eosinophil based treatment, the outcome, measured in patient-reported symptoms and quality of life, showed equal efficacy. ${ }^{58}$ Exacerbations, a too-often forgotten aspect of asthma, were 3 times as common in the guideline-based treatment as in the sputum group. In another long-term trial with a success definition based on proxies of GINA control including shortacting beta agonist and oral steroid use, long-acting beta-2 agonist treatment gave a higher chance of achieving control than using increased inhaled steroids. ${ }^{59}$ When analyzed for exacerbations, steroid use was much more effective. So, as with patients, we need a broad range of outcome measures in asthma to help us determine real effectiveness.

\section{How should we see the data?}

Mean data, as a basis for making decisions, can be very misleading. Information on the range of responses can reveal quite different information and yet is often not presented meaning the potential for a different insight is lost. A trial in children that showed that half the children did equally well on leukotriene antagonists and ICS, but the cross-over data showed that 1 in 3 children did better on inhaled steroid and 1 in 6 did better on leukotriene antagonists. ${ }^{60}$ This would suggest that guideline-based recommendations to step up treatment may be missing the point that changing the treatment may bring a better result. As another example, the Greening trial of long-acting beta- 2 agonists vs increased ICS showed that patients did about equally well on both treatments. ${ }^{61}$ Closer examination of the data, however, revealed that some patients did very well on the long-acting beta- 2 agonist (LABA), and some did very well on the ICS. Ideally, we should always see the distribution of data as well as the mean results to ensure that these variations in response are identified.

\section{Guidelines}

Looking at the British guidelines on the management of asthma, as an example, we see the statement that: "inhaled steroids are the most effective preventer drug for adults and older children for achieving overall treatment goals. In fact, the word effective here should be efficacious, as effectiveness has never been tested. As a demonstration of the difference, a recent government-sponsored pragmatic trial, an economic assessment of the use of leukotriene antagonists in primary care at step 2 of the UK national asthma guidelines $\left(\right.$ Elevate $^{62}$ ) was carried out over 2 years. This was performed in a relatively unrestricted population, including smokers and patients with relatively poor reversibility. While the end result in terms of lung function and quality of life showed almost exactly equally effectiveness, analysis of adherence showed that the leukotriene antagonists achieved $61.4 \%$ adherence to treatment vs $41.1 \%$ for ICS. This demonstrates the difference between efficacy and effectiveness in a more real-world setting. A comparison of the demographics and drop-out rate of Elevate, ${ }^{62} \mathrm{GOAL},{ }^{44}$ and the IMPACT (Improving Asthma Control Trial) study ${ }^{63}$ showed a significant difference in how close the patient population in these trials was to a real-life distribution and how this can potentially impact on the applicability of these trials' results to everyday clinical effectiveness.

Another statement from the UK asthma guidelines is as follows: "In adults, there is no clinical difference in effectiveness of pMDI \pm spacer $v$ DPI. Breath-actuated MDI is as effective as pMDI. More recent DPIs are as effective as older DPIs." Does anybody believe this? Why does it say this, when we all know that it's not true? It is because of the evidence hierarchy; in the randomized controlled trials on which it is based, patients were excluded if they could not operate both a pMDI and a breath-actuated inhaler (BAI) effectively. Unsurprisingly, therefore, the trial concluded that they were both equally effective!

Compare that "finding" with a more "real-life," observational study. Analyzing a general practice database of patients who either started on ICS for the first time, or who had an increase in their dose, a 1-year baseline period to define confounding factors/match populations was followed by a 1-year outcome period. ${ }^{64}$ The results showed an increased chance of gaining control with a BAI or DPI vs a pMDI, in both first-use and increased-dosage groups. So the device does matter. The guidelines, had they been based on a range of evidence as opposed to the evidence hierarchy, would have come to much more sensible conclusions.

One more example: the guidelines state: "Many studies now show Qvar ${ }^{\circledR}$ equivalence at half the dose of CFC-BDP pMDI ${ }^{65}$ whereas non-Qvar ${ }^{\circledR}$ HFA-BDP pMDI studies show equivalence at $1: 1$ dosing." That is what the randomized trials 
show - in classical asthma; but people with poor technique were excluded, as were patients with unstable asthma, with frequent exacerbations who, as we have heard, may have more small airways involvement. What about more real-life patients? There is a 1 -year pragmatic trial of patients with stable asthma, where patients were given half the dose of Qvar ${ }^{\circledR}$ or the full dose of CFC-BDP, ${ }^{66}$ with a significant difference in quality of life and symptom-free days at 12 months.

I hope I have challenged your thinking about evidencebased medicine; do you think that Sir Michael Rawlins was right, that we need a new approach to evidence? That we need to take the whole range of evidence into account, looking at study designs to make sure of external as well as internal validity, a variety of outcomes, a true intention to treat approach? If we do we will often get results that surprise us. We have to deal with the whole range of people with asthma and to do whatever we need to for them, however strange it might be.

\section{Real-life device trials Professor Nicolas Roche, Hôtel-Dieu, Paris}

Three factors are major determinants of appropriate treatment delivery with inhaler therapy, since they condition particle size (mass median aerodynamic diameter) and respiration mass/fraction: the device itself, such factors as internal resistance; the device contents, ie, pharmacological agent, excipients, propellants; and the inhalation technique. With MDIs, including BAIs, the content is actively propelled towards the airways; with DPIs the act of inhalation is the only propellant - inhalation has to be fast and furious. The ideal device would require no co-operation by the patient - such a device does not exist. Inhalation technique is usually well controlled in randomized trials but not in real life. Therefore, controlled studies are not sufficient to get an accurate picture of the results that will be obtained in the real-world patient's life.

\section{Why is it important to perform real-life studies on inhalation technique and devices?}

What we would hope to achieve with ICS is that the majority of asthma patients would be well controlled, and a significant proportion would be totally controlled. What is actually seen in large surveys of the general population is that about $5 \%$ of asthmatics are controlled. ${ }^{67}$ In a real-life study of general practice $28 \%$ were controlled, either acceptably (7\%) or optimally (21\%), while $72 \%$ were not acceptably controlled. ${ }^{68}$
Table 3 Possible reasons for such suboptimal levels of control

Insufficiently rigorous assessment of control

Inadequate maintenance therapy

Rhinitis, GER

Environmental exposures

Smoking

Being overweight

Device and Inhalation technique problems

Poor compliance

Abbreviation: GER, gastroesophageal reflux.

The reasons for such suboptimal levels of control are shown in Table 3.

\section{Accuracy of assessment and perception}

The accuracy of assessments of control is an important issue; the same population in which control was found to be unacceptable in $72 \%$, when asked how their asthma was, actually reported that it was badly controlled in only $8 \%$, moderately in $39 \%$, well in $32 \%$, and perfectly in $21 \%$. So differences in perception play a major part in evaluations, an issue confirmed by comparisons across the world of patient-perceived control vs severity of symptoms. In another comparison of physician-reported symptom occurrence vs patient-reported symptom occurrence, very large discrepancies were shown between the two, with patients reporting almost 6 times the incidence of symptoms, such as speaking problems, compared with the physicians.

These problems of assessment are true for inhalation technique as well as control, many physicians underestimating the proportion of device misuse by patients ${ }^{69}$ and overestimating the education they give to patients about inhaler use. Studies found that inhalation technique was not appropriate in health professionals either: inappropriate technique was observed in $65 \%$ of nurses, $63 \%$ of general practitioners, $53 \%$ of fellows, and $15 \%$ of specialists. Education in inhaler technique requires a cycle of explanation, demonstration, checking of the patient's technique, and then repeating or, if necessary, changing the device type if correct performance is not achieved. Such education is very important; with some devices, patient education has been shown to reduce the rate of critical errors from almost $60 \%$ to around $10 \%$ of patients. Critical errors, defined as errors that could substantially affect the dose delivered to the lung, can be nonspecific to a particular device, such as failure to inhale through the mouthpiece, or device-specific, such as blowing into a DPI before inhalation. In a study of 3811 patients using a variety of inhalers, $76 \%$ of patients made at least one error with pMDI compared with $49 \%$ to $55 \%$ with BAIs (Figures 2 and 3 ). ${ }^{70}$ 


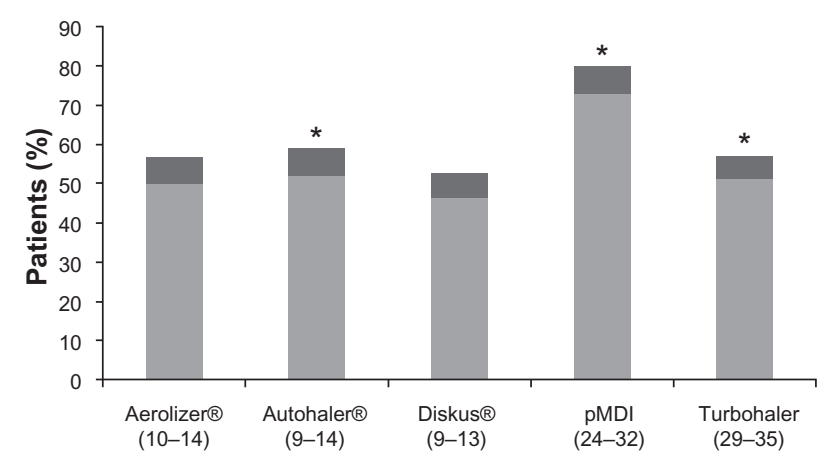

Figure 2 Percentage of patients making at least one error using their inhaler. ${ }^{70}$ Note: $* p<0.05$ compared with the best result $(95 \% \mathrm{Cl})$.

Abbreviations: $\mathrm{Cl}$, confidence intervals; PMDI, metered dose inhaler.

What are the consequences of poor inhalation technique in real life? Inhalation technique is critical to the success of asthma therapy, poor technique with MDIs causing $60 \%$ lower lung deposition and 30\% less bronchodilation, and thus poor asthma control. In a study in which patients were treated for the lung deposition achieved by 18 patients using a pMDI or a BAI, poor pMDI co-ordinators achieved lung deposition less than $7 \%$ of the dose, good pMDI coordinators $25 \%$ of the dose and BAI users $23 \% .^{71}$ In another study of errors and omissions among 3955 unselected asthmatics on pMDI-delivered ICS were recorded ${ }^{72}$ (Table 4).

The consequences of the above errors and omissions showed clearly in the asthma control outcome of these patients, demonstrating also the fact that, even in good coordinators, other errors can compromise long-term asthma control. Evaluation of medical visits by asthmatics demonstrates a rise in emergency visits and increased beta agonist use with inhaler misuse, made worse still by poor co-ordination. Unsurprisingly, this is also confirmed by the effect of correcting inhaler use to increase the efficiency of inhalation flow by means of training devices, questioning, and education

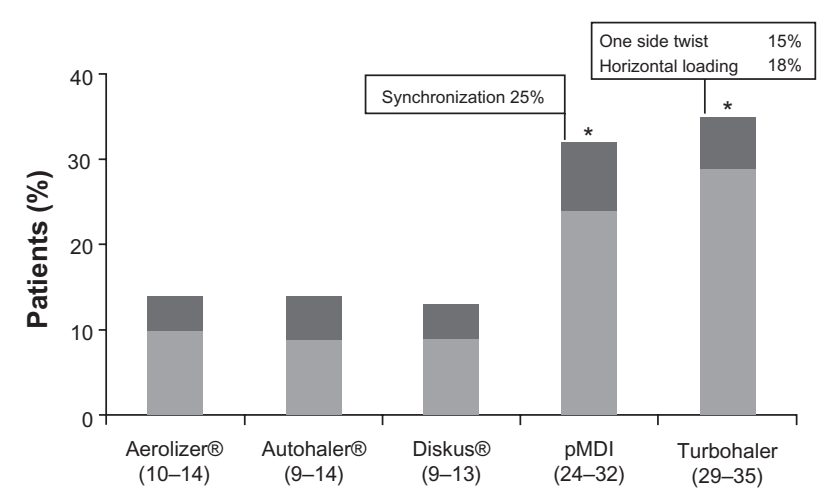

Figure 3 Percentage of patients making at least one critical error. ${ }^{70}$ Note: $* P<0.05$ compared with the best result $(95 \% \mathrm{Cl})$. Abbreviations: $\mathrm{Cl}$, confidence intervals; PMDI, metered dose inhaler.
Table 4 Errors and omissions among unselected asthmatics on PMDI-delivered ICS $^{70}$

\begin{tabular}{lll}
\hline Cause of misuse & $\mathbf{n}$ & $\%$ \\
\hline Omissions & 16 & 0 \\
No removal of cap & 260 & 7 \\
Inhaler not held correctly & 748 & 19 \\
$\begin{array}{l}\text { Device not actuated at the } \\
\text { beginning of the inspiration }\end{array}$ & 1348 & \\
No slow inspiratory flow & 919 & 34 \\
No complete inspiration & 739 & 23 \\
$>$ I puff & 1753 & 19 \\
No 5-s breath holding period & & 44 \\
at the end of inspiration & & \\
Errors & 1077 & 27 \\
Forced expiration & 440 & 11 \\
No expiration & 480 & 12 \\
Inspiration by nose & 708 & 18 \\
Actuation at the end & & \\
of inspiration & 224 & 6 \\
No inspiration &
\end{tabular}

Abbreviations: ICS, inhaled corticosteroids; PMDI, metered dose inhaler.

by a health professional. In a study in which 256 trained pharmacists asked 727 patients about control and compliance, checked inhaler technique, and gave education for a mean of 6 minutes on 2 occasions, optimal technique increased from 176 patients $(25 \%)$ to $678(80 \%){ }^{73}$ Significantly, $67 \%$ of patients reported that they had never previously used a device in front of a health professional. Importantly, improvement in inhalation technique was accompanied by better asthma control and adherence to treatment at 1 month.

\section{Can the device influence control in real life?}

An analysis of the Doctors' Independent Network database (DIN-LINK) primary care database of treatment of asthmatic children ${ }^{74}$ has demonstrated a relationship between the device type and indicators of poor control; children using a breath-actuated device required less beta- 2 agonists, less oral steroids, less antibiotics, and made fewer visits to their general practitioner for asthma problems.

A series of very large-scale studies of the UK GPRD from 1997 to 2006 are in progress to attempt to answer the question: "Does the device/formulation used to administer ICS change anything in asthma or COPD control?" The studies deal with:

- HFA extra-fine particle betamethasone dipropionate (BDP) $\left(\right.$ Qvar $\left.^{\circledR}\right)$ vs fluticasone in asthma (concerning the effect of formulation)

- HFA-BDP vs CFC-BDP in asthma

- Fixed-dose ICS/LABA combinations in pediatric asthma

- CFC-BDP vs fluticasone proprionate in COPD 
For all these analyses, the study period for each patient includes the 12 months before (baseline) and after (outcome) an index event, which is a first prescription or first increase of ICS. The patient age range is 5 to 60 years, and careful matching and historical data standards are incorporated into the protocols. Primary outcomes are a composite proxy measure of control (no emergency visits or oral steroids) and exacerbations requiring hospital treatment or oral steroids. A secondary outcome is treatment failure leading to exacerbation or treatment increase. When adjustments for baseline differences between the treatment arms are not sufficient, matching ensures that treatment groups are comparable. Matching variables include age, height, weight, sex; asthma consultations; and - for the ICS increase cohort only - prior ICS dose.

Initial results for the Qvar ${ }^{\circledR}$ vs fluticasone analysis, after matching for severity, are that:

- Doses of extra-fine HFA-BDP $\left(\right.$ Qvar $\left.^{\circledR}\right)$ are half that of fluticasone proprionate

- Patients in the extra-fine HFA-BDP $\left(\right.$ Qvar $\left.^{\circledR}\right)$ group

- Are more frequently controlled

- Have more treatment success

- Have less treatment increases

- Suggesting an increased efficacy when the ICS is delivered as extra-fine particles

\section{Conclusion}

Real-life studies demonstrate that

- Asthma control is suboptimal,

- Poor inhalation technique is frequent, and decreases asthma control

- Misuse occurs with all device types

- Healthcare professionals are insufficiently aware of these issues

- Education can improve:

- Inhalation technique

- Compliance

- Control

- Control can also be influenced by:

- The device

- The formulation

\section{Disclosure}

This report is written as a summary from a meeting supported by Teva Pharmaceutical Industries Limited, Petach Tikva, Israel. The writing and publication costs were covered by Teva Pharmaceutical Industries Limited. All the presenters were paid by Teva Pharmaceutical Industries
Limited to attend the meeting but the views and opinions are those of the presenters and not necessarily those of Teva Pharmaceutical Industries Limited.

\section{References}

1. Mauad T, Silva LFF, Santos MA. Abnormal alveolar attachments with decreased elastic fiber content in distal lung in fatal asthma. AJRCCM. 2004; 170:857-862.

2. Kim V, Rogers TJ, Criner GJ. New concepts in the pathobiology of chronic obstructive pulmonary disease. Proc Am Thorac Soc. 2008;5: 478-485.

3. Yanai M, Sekizawa K, Ohrui T, et al. Site of airway obstruction in pulmonary disease: direct measurement of intrabronchial pressure. J Appl Physiol. 1992;72(3):1016-1023.

4. Borgstrom L, Bengtsson T, Derom E, Pauwels R. Variability in lung deposition of inhaled drug, within and between asthmatic patients. Int J Pharm. 2000;193:227-230.

5. Hamid QA. Peripheral inflammation is more important than central inflammation. Respir Med. 1997;91(Suppl A):11-12.

6. Leach CL, Davidson PJ, Hasselquist BE, Boudreau RJ. Lung deposition of hydrofluoroalkane-134a beclomethasone is greater than that of chlorofluorocarbon fluticasone and chlorofluorocarbon beclomethasone. Chest. 2002;122:510-516.

7. Lipworth BJ, Jackson CM. Pharmacokinetics of chlorofluorocarbon and hydrofluoroalkane metered-dose inhaler formulations of beclomethasone dipropionate. Br J Clin Pharmacol. 1999;48:866-868.

8. Usmani Biddiscombe MF, Barnes PJ. Regional Lung Deposition and Bronchodilator Response as a Function of beta2-Agonist Particle Size. AJRCCM. 2005;172:656-657.

9. Newman SP. A comparison of lung deposition patterns between different asthma inhalers. J Aerosol Med. 1995;8(Suppl 3):S21-S26 discussion S27.

10. Leach CL. Improved delivery of inhaled steroids to the large and small airways. Respir Med.1998;92(Suppl A):3-8.

11. Leach CL. Improved airway targeting with the CFC-free HFAbeclomethasone metered-dose inhaler compared with CFCbeclomethasone. Eur Respir J. 1998;12:1346-1353.

12. Leach CL. Targeting inhaled steroids. Int J Clin Pract Suppl. 1998;96: 23-27.

13. Usmani OS, Biddiscombe MF, Barnes PJ. Regional lung deposition and bronchodilator response as a function of beta2-agonist particle size. AJRCCM. 2005;172:656-657.

14. Veen JC, Beekman AJ, Bel EH, Sterk PJ. Recurrent exacerbations in severe asthma are associated with enhanced airway closure during stable episode. Am J Respir Crit Care Med. 2000;161;1902-1906.

15. Berry M, Hargadon B, Morgan A, et al. Alveolar nitric oxide in adults with asthma: evidence of distal lung inflammation in refractory asthma. Eur Respir J. 2005;25:986-991.

16. Van Essen-Zandvliet EE, Hughes MD, Waalkens HJ, et al. Effects of 22 months of treatment with inhaled corticosteroids and/or beta-2-agonists on lung function, airway responsiveness, and symptoms in children with asthma. Am Rev Respir Dis. 1992;146: $547-554$.

17. Global Strategy for the Diagnosis and Management of Asthma in Children 5 years and Younger, Global Initiative for Asthma (GINA) 2006. http://www.ginasthma.org. Accessed April 14, 2011.

18. Brand PL, Baraldi E, Bisgaard H, et al. Definition, assessment and treatment of wheezing disorders in preschool children: an evidence-based approach. Eur Respir J. 2008;32:1096-1100.

19. Janssens HM, De Jongste JC, Hop WC, et al. Extra-fine particles improve lung delivery of inhaled steroids in infants: a study in an upper airway model Chest. 2003;123:2083-2088.

20. Janssens HM, De Jongste JC, Fokkens WJ. The Sophia Anatomical Infant Nose-Throat (Saint) model. J Aerosol Med. 2001;4:433-441. 
21. Schüepp KG, Jauernig J, Janssens HM, et al. In vitro determination of the optimal particle size for nebulized aerosol delivery to infants. J Aerosol Med. 2005;18:225-235.

22. Mallol J, Rattray S, Walker G, Cook D, Robertson CF. Aerosol deposition in infants with cystic fibrosis. Pediatr Pulmonol. 1996;21:276-281.

23. Schüepp KG, Straub D, Möller A, Wildhaber JH. Deposition of aerosols in infants and children. J Aerosol Med. 2004;17:153-156.

24. Köhler E, Jilg G, Avenarius S, Jorch G. Lung deposition after inhalation with various nebulizers in preterm infants. Arch Dis Child Fetal Neonatal Ed. 2008;93:F275-F279.

25. Schüepp KG, Devadason SG, Roller C, et al. Aerosol delivery of nebulizer budesonide in young children with asthma. Respir Med. 2009;103: $1738-1745$.

26. Agertoft L, Laulund LW, Harrison LI, Pederson S. Influence of particle size on lung deposition and pharmacokinetics of beclomethasone dipropionate in children. Pediatr Pulmonol. 2003;35:192-199.

27. Nayak A, Lanier R, Weinstein S, Stampone P, Welch M. Efficacy and safety of beclomethasone dipropionate extrafine aerosol in childhood asthma. Chest. 2002;122:1956-1965.

28. Van Aalderen WM, Price D, De Baets FM, Price J. Beclometasone dipropionate extrafine aerosol versus fluticasone propionate in children with asthma. Respir Med. 2007;101:1585-1593.

29. Szefler SJ, Warner J, Staab D, et al. Switching from conventional to extrafine aerosol beclomethasone dipropionate therapy in children. J Allergy Clin Immunol. 2002;110:45-50.

30. Inhaled Particles VII, International Symposium on Inhaled Particles 16-22 September 1991. Edinburgh, Scotland). Pergamon Press, 1992. ISBN 0080408419.

31. Skoner DP, Maspero J, Banerji, et al. Assessment of the long-term safety of inhaled ciclesonide on growth in children with asthma. Pediatrics. 2008;121:1-14.

32. Pedersen S, Warner J, Wahn U, et al. Growth, systemic safety, and efficacy during 1 year of asthma treatment with different beclomethasone dipropionate formulations. Pediatrics. 2002;109:e92.

33. Carroll N, Elliot J, Morton A, James A. The structure of large and small airways in nonfatal and fatal asthma. Am Rev Respir Dis. 1993;147: 405-410.

34. Wagner EM, Liu MC, Weinmann GG, Permutt S, Bleecker ER. Peripheral lung resistance in normal and asthmatic subjects. Am Rev Respir Dis. 1990;141(3):584-588.

35. Irvin CG, Pak J, Martin RJ. Airway-parenchyma uncoupling in nocturnal asthma. Am J Respir Crit Care Med. 2000;161:50-56.

36. Kraft M, Djukanovic R, Wilson S, Holgate ST, Martin RJ. Alveolar tissue inflammation in asthma. Am J Respir Crit Care Med. 1996;154: 1505-1510.

37. Goldin JG Tashkin DP, Kleerup EC, et al. Comparative effects of hydrofluoroalkane and chlorofluorocarbon beclomethasone dipropionate inhalation on small airways. J Allergy Clin Immunol. 1999;104: 258-267.

38. Ford PA, Russell REK, Barnes PJ. ICS and COPD: Time to clear the air. Int J Chron Obstruct Pulmon Dis. 2009;4:289-290.

39. Weatherall M, Shirtcliffe P, Travers J, Beasley, R. Use of cluster analysis to define COPD phenotypes. Eur Respir J. 2010;36:472-474.

40. Drummond MB, Dasenbrook EC, Pitz MW, et al. Inhaled corticosteroids in patients with stable chronic obstructive pulmonary disease. JAMA. 2008;26:300:2407-2416.

41. Starkie HJ, Briggs AH, Chambers MG. Pharmacoeconomics in COPD: Lessons for the future. Int J Chron Obstruct Pulmon Dis. 2008;3:71-88.

42. Britton M. The burden of COPD in the UK.: results from the Confronting COPD survey. Respir Med. 2003;97(Suppl C):S71-S79.

43. Hole DJ, Watt GC, Davey-Smith G, Hart CL, Gillis CR, Hawthorne VM. Impaired lung function and mortality risk in men and women: findings from the Renfrew and Paisley prospective population study. BMJ. 1996;313:711-715.

44. Bateman E, Boushey HA, Bousquet, et al. Can guideline-defined asthma control be achieved? Am J Respir Crit Care Med. 2004;170:836-844.
45. Briggs AH, Bousquet J, Wallace MV, et al. Cost-effectiveness of asthma control: an economic appraisal of the GOAL study. Allergy. 2006;61: 531-536.

46. Calverley PMA, Anderson JA, Celli B, et al. Salmeterol and fluticasone propionate and survival in chronic obstructive pulmonary disease. N Engl J Med. 2007;356:775-789.

47. Briggs A, Glick HA, Lozano-Ortega G, et al. Is treatment with ICS and LABA cost-effective for COPD? Multinational economic analysis of the TORCH study. Eur Respir J. 2010;35:532-539.

48. Jonasson G, Carlsen KH, Mowinckel P. Asthma drug adherence in a long term clinical trial. Arch Dis Child. 2000;83:330-333.

49. Smith GC, Pell JP. Parachute use to prevent death and major trauma related to gravitational challenge: systematic review of randomised controlled trials. BMJ. 2003;327:1459-1461.

50. Vestbo J. The TORCH study Group. The TORCH (TOwards a Revolution in COPD Health) survival study protocol. Eur Respir J. 2004;24: 206-210.

51. Tashkin DP, Celli B, Senn S, et al. A 4-year trial of tiotropium in chronic obstructive pulmonary disease. N Engl J Med. 2008;359:1543-1554.

52. Herland K Akselsen JP, Skjønsberg OH, Bjermer L. How representative are clinical study patients with asthma or COPD for a larger and "real life" population of patients with obstructive lung disease? Respir Med. 2005;99:11-19.

53. GiraudV, Roche N. Misuse of corticosteroid metered-dose inhaler is associated with decreased asthma stability. Eur Respir J. 2002;19:246-251.

54. Clatworthy J, Price D, Ryan D, Haughney J, Horne R. The value of self-report assessment of adherence, rhinitis and smoking in relation to asthma control. Prim Care Respir J. 2009;18:300-330.

55. Chaudhuri R, Livingston E, McMahon AD, et al. Effects of smoking cessation on lung function and airway inflammation in smokers with asthma. Am J Respir Crit Care Med. 2006;174:127-133.

56. Barnes PJ, Ito K, Adcock IM. Corticosteroid resistance in chronic obstructive pulmonary disease. Lancet. 2004;363:731-733.

57. Fauler J, Frölich JC. Cigarette smoking stimulates cysteinyl leukotriene production in man. Eur J Clin Invest. 1997;27:43-47.

58. Green RH, Brightling CE, McKenna S, et al. Asthma exacerbations and sputum eosinophil counts: a randomised controlled trial. Lancet. 2002;360:1715-1721.

59. Thomas M, von Ziegenweidt J, Lee AJ, Price D. High-dose inhaled corticosteroids versus add-on long-acting beta-agonists in asthma: an observational study. J Allergy Clin Immunol. 2009;123:116-121.

60. Zeiger RS, Szefler SJ, Phillips BR, et al. Response profiles to fluticasone and montelukast in mild-to-moderate persistent childhood asthma. J Allergy Clin Immunol. 2006;117:45-52.

61. Greening AP, Ind PW, Northfield M, Shaw G. Added salmeterol versus higher-dose corticosteroid in asthma patients with symptoms on existing inhaled corticosteroid. Lancet. 1994;344:219-224.

62. A pragmatic single-blind RCT and health economic evaluation of leukotriene receptor antagonists in primary care at steps two and three of the national asthma guidelines (ELEVATE) http://www.hta.ac.uk/ project/1204.asp. Accessed April 14, 2011.

63. Bjermer L, Bisgaard H, Bousquet J, et al. Montelukast and fluticasone compared with salmeterol and fluticasone in protecting against asthma exacerbation in adults: a one year, double blind, randomized controlled trial. BMJ. 2003;327:891.

64. Price D, Haughney J, Sims E, et al. Effectiveness of inhaler types for real-world asthma management: retrospective observational study using the GPRD. Journal of Asthma and Allergy 2011;4:37-47.

65. Fireman P, Prenner BM, Vincken W, Demedts M, Mol SJ, Cohen RM. Long-term safety and efficacy of a chlorofluorocarbon-free beclomethasone dipropionate extrafine aerosol. Ann Allergy Asthma Immunol. 2001;86:557-565.

66. Price D, Martin RJ, Barnes N, et al. Prescribing practices and asthma control with hydrofluoroalkane-beclomethasone and fluticasone: a real-world observational study. J Allergy Clin Immunol. 2010;126: $511-518$. 
67. Rabe KF, Vermeire PA, Soriano JB, Maier WC. Clinical management of asthma in 1999: the Asthma Insights and Reality in Europe (AIRE) study. Eur Respir J. 2000;16:802-807.

68. Godard P, Huas D, Sohier B, Pribil C, Boucot I. Asthma control in general practice: a cross-sectional survey of 16,580 patients. Presse Med. 2005;5:34(19 Pt 1):1351-1357.

69. Megas F. The "Compli'Asthme" therapeutic observation survey on good use of inhaled drugs for asthma: perception by general practitioners. Rev Pneumol Clin. 2004;60:158-165.

70. Molimard M, Raherison C, Lignot S, et al. Assessment of handling of inhaler devices in real life: an observational study in 3811 patients in primary care. J Aerosol Med. 2003;16:249-254.
71. Newman SP, Weisz AW, Talaee N, Clarke SW. Improvement of drug delivery with a breath actuated pressurized aerosol for patients with poor inhaler technique. Thorax 1991;46:712-716.

72. Giraud V, Roche N. Misuse of corticosteroid metered-dose inhaler is associated with decreased asthma stability. Eur Respir J. 2002;19: 246-251.

73. Al-Showair RAM, Pearson SB, Chrystyn H. The potential of a 2Tone Trainer to help patients use their metered-dose inhalers. Chest. 2007; 131:1776.

74. Price D, Thomas M, Mitchell G, Niziol C, Featherstone R. Improvement of asthma control with a breath-actuated pressurised metred dose inhaler (BAI). Respir Med. Jan 2003;97(1):12-19.

\section{Publish your work in this journal}

The Journal of Asthma and Allergy is an international, peer-reviewed open-access journal publishing original research, reports, editorials and commentaries on the following topics: Asthma; Pulmonary physiology; Asthma related clinical health; Clinical immunology and the immunological basis of disease; Pharmacological interventions and
Dovepress

new therapies. Issues of patient safety and quality of care will also be considered. The manuscript management system is completely online and includes a very quick and fair peer-review system, which is all easy to use. Visit http://www.dovepress.com/testimonials.php to read real quotes from published authors.

Submit your manuscript here: http://www.dovepress.com/journal-of-asthma-and-allergy-journal 